\title{
PERSEPSI BUNYI HENTIAN BERSUARA BAHASA INDONESIA OLEH PEMELAJAR TAIWAN
}

\author{
Johnny Lee \\ National Chi Nan University; National Taiwan Normal University, Taiwan \\ E-mail: johnny.lie84@gmail.com
}

\begin{abstract}
This study investigated the perception performance of the voiced stops of Indonesian language by Taiwanese learners. Previous studies suggest that the perception of foreign languages' phonemic category absent in the L1 inventory is troublesome, and this is also the case for the Taiwanese learners' of Indonesian. Seven of eight of our subjects were unable yet to perfectly distinguish between the voiced stops $[b, d, g]$ and their voiceless counterpart $[p, t, k]$ despite being able to speak Taiwanese (Southern Min) which has the voicing distinction for bilabial stops $[b]-[p]$ and velar stops $[g]-[k]$. The result yielded from a small sized experimental study of forced option test and literature study provides us a preliminary understanding on why some Taiwanese learners sometimes made production errors, oral and written. This study serves as a preliminary study which we hope to lead to a bigger-scale and well-controlled psychoacoustics study in the future in order to have a more definitive result on the perceptional issue by Taiwanese learners of Indonesian.
\end{abstract}

Keywords: perception; voiced; voiceless; stops; Indonesian; Taiwanese

\begin{abstract}
Abstrak: Studi ini meneliti kemampuan persepsi pemelajar Taiwan terhadap bunyi konsonan hentian bersuara bahasa Indonesia. Penelitian sebelumnya menunjukkan bahwa pemelajar bahasa asing memiliki kesulitan mempersepsi terhadap bunyi-bunyi bahasa asing yang tidak dimiliki oleh kategori fonem bahasa pertama dan kondisi yang sama juga dijumpai pada pemelajar bahasa Indonesia sebagai bahasa asing asal Taiwan. Tujuh dari delapan subjek penelitian masih belum mampu untuk secara sempurna membedakan konsonan hentian bersuara $[\mathrm{b}, \mathrm{d}, \mathrm{g}]$ dan pasangan takbersuaranya $[\mathrm{p}, \mathrm{t}, \mathrm{k}]$ meski semua subjek mampu berbahasa Taiwan (Min Selatan) yang memiliki pembedaan ciri suara pada konsonan hentian bilabial [b][p] dan bunyi konsonan hentian velar [g]-[k]. Hasil yang dihasilkan dari penelitian eksperimen dengan teknik force option test dan rujukan kepustakaan berskala kecil ini memberikan gambaran awal tentang kemungkinan penyebab pemelajar bahasa Indonesia asal Taiwan terkadang membuat kekeliruan produksi bahasa, baik secara lisan maupun tulisan. Penelitian ini berfungsi sebagai studi awal yang diharapkan bisa diteruskan untuk penelitian berskala besar dan menggunakan metode psikoakustik untuk mendapatkan hasil yang lebih definitif terhadap isu persepsi pemelajar bahasa Indonesia asal Taiwan.
\end{abstract}

Kata Kunci: persepsi; bersuara; tak bersuara; konsonan hentian; bahasa Indonesia pemelajar Taiwan

Permalink/DOI: http:/ /dx.doi.org/10.15408/dialektika.v5i1.16629 


\section{Pendahuluan}

Setiap bahasa di dunia memiliki kategori fonem masing-masing. Kuhl menyatakan bahwa pemerolehan kategori fonem ini dapat dengan mudah diperoleh pada masa usia 0-1 tahun. ${ }^{1} \mathrm{Hal}$ serupa disampaikan Carrol bahwa bayi pada usia 4 bulan sudah mulai mempersepsi bunyi /ba/ dan /pa/ dengan VOT 20-30 milisekon. ${ }^{2}$ Carrol pun menjelaskan bahwa bayi terlahir dengan kemampua untuk mendistingsi sejumlah fonem. ${ }^{3}$ Persepsi bunyi bahasa ini erat kaitannya dengan kepekaan (awareness) atas fungsi auditori dan memori dari penutur. ${ }^{4}$ Selain itu, persepsi terhadap bunyi juga berkaitan dengan pengenalan dan identifikasi seseorang terhadap segmen fonetik. ${ }^{5}$

Namun demikian, ketika sistem fonem seseorang sudah terbentuk, biasanya pemerolehan kategori perspepsi baru akan sulit dilakukan kecuali seseorang diberikan dengan masukan dan pelatihan yang memadai. Pentingnya faktor kuantitas dan kualitas masukan ini dikemukakan oleh Flege. ${ }^{6}$ Pemelajar Taiwan juga mengalami kesulitan yang serupa ketika memelajari bahasa Indonesia, bahasa yang memiliki fitur distingtif pada kategori suara [+suara] dan [-suara] pada konsonan hentian. Akibatnya, kadang ditemukan tertukarnya antara konsonan hentian takbersuara dengan versi bersuaranya pada bahasa tulis, seperti bapak dengan babak dan karena dengan garena. Namun sebaliknya, pada saat artikulasi, pemelajar melafalkan konsonan bersuara dengan konsonan takbersuara, seperti [dua] menjadi [tua] atau dengan varian takbersuara aspirasi yang tidak terdapat dalam kategori fonem bahasa Indonesia [thua].

1 Patricia. "Early language acquisition: cracking the speech code". Nature reviews Neuroscience, 5(11), 2004, hal. 832-833.

${ }^{2}$ David W. Carroll, Phychology of Language Fifth Edition, (Australia: Thomson Wandswort), 2008, hal. 258.

${ }^{3}$ David W. Carroll, Phychology of Language Fifth Edition ..... hal. 259.

${ }^{4}$ Reetz dan Jongman, Phonetics: Transcription, Production, Acoustics, and Perception, New York: John Wiley \& Sons, 2011, hal. 19.

${ }^{5}$ Katrina Hayward, Experimental Phonetics: An Introduction. New York: Routledge, 2014, 105.

${ }^{6}$ Flege, J. "The instrumental study of L2 speech production: Some methodological considerations”. Language Learning, 37, 1987, hal. 285-296. 
Terkait dengan pemerolehan kategori persepsi fonemik, Kuhl menyatakan bahwa pemerolehan bahasa kedua terganggu oleh bahasa pertama. Efek gangguan tersebut semakin tampak pada pembedaan fitur fonemik, khususnya fitur-fitur yang tidak terdapat pada bahasa pertama pemelajar bahasa tersebut. Contoh yang terkenal dapat ditemukan pada penelitian Miyazaki, dkk. terhadap orang Jepang yang memelajari bahasa Inggris. ${ }^{8}$ Bahasa Jepang tidak memiliki pembedaan kategori fonemik antara konsonan likuid [r] dan [1]. Akibatnya, subjek orang Jepang pada studi ini tidak bisa membedakan bunyi [ra] dan [la] bahkan sesudah mendapatkan pelatihan bahasa Inggris selama 10 tahun.

Kondisi yang sama dapat ditemukan pada penutur bahasa Mandarin sebagai bahasa dominan yang memelajari bahasa Indonesia di kelas Bahasa Indonesia untuk Penutur Asing (BIPA) di Taiwan. Bahasa Mandarin memiliki dua kategori konsonan hentian, takbersuara dan aspirasi. Sementara itu, bahasa Indonesia memiliki satu kategori yang salah satunya tidak terdapat pada bahasa Mandarin, konsonan hentian bersuara. Namun demikian, semua subjek yang peneliti teliti adalah orang bilingual (bahasa Mandarin-bahasa Taiwan dan bahasa Mandarin-bahasa Hakka) yang mana bahasa Taiwan memiliki pembedaan pada fitur suara pada konsonan hentian bilabial dan velar.

Berbeda dengan Miyazaki, dkk., ${ }^{9}$ penelitian Bradlow, dkk., ${ }^{10}$ dan Wang, dkk. ${ }^{11}$, menunjukkan bahwa pemerolehan kategori bunyi non-jati bukanlah hal yang mustahil dan dapat ditingkatkan kemampuannya. Pada penelitian ini, peneliti mengharapkan bahwa subjek pemelajar Taiwan memiliki kemampuan persepsi terhadap kontras suara yang terdapat pada bahasa Indonesia, dalam tingkatan yang berbeda.

\footnotetext{
${ }^{7}$ Patricia Kuhl, “A New View of Language Acquisition”, Proceedings of the National Academy of Sciences, 97(22), 2000, hal. 175-190.

${ }^{8}$ K. Miyazaki, dkk. "An effect of linguistic experience: The discrimination of $[\mathrm{r}]$ and $[\mathrm{l}]$ by native speakers of Japanese and English". Perception and Psychophysics, 18.5, 1975, hal. 331-340.

${ }^{9}$ K. Miyazaki, dkk. "An effect of linguistic experience: The discrimination of [r] and [l] by native speakers of Japanese and English”. Perception and Psychophysics, 18.5, 1975

${ }^{10}$ Bradlow, dkk. "Training Japanese listeners to identify English /r/ and /l/: IV. Some effects of perceptual learning on speech production”. Journal of the Acoustical Society of America, 101, 1997, hal. 2301-2302.

${ }^{11}$ Wang, dkk., “Training American Listeners to Perceive Mandarin Tones”. Journal of the Acoustical Society of America, 106, 1999, hal. 3649-3659.
} 
Tulisan ini mengkaji kemampuan persepsi fonologi fitur suara pemelajar Taiwan. Penelitian ini menggunakan teknik tes diskriminasi untuk membandingkan kemampuan subjek pemelajar Taiwan dan penutur bahasa Indonesia, yang tumbuh besar di lingkungan berbahasa Indonesia. Pada penelitian ini, peneliti juga meminta subjek untuk mengisi kuesioner tentang latar belakang/profil kebahasaan mereka.

\section{Metode}

Penelitian ini menggunakan tugas diskriminasi (discrimination task) untuk mengetahui kemampuan persepsi pemelajar Taiwan terhadap bunyi konsonan hentian bersuara; untuk mengetahui apakah pemelajar Taiwan mampu menentukan batas fonem (phonemic boundary) untuk fitur suara konsonan hentian. Studi ini menggunakan tes pelabelan di mana diberikan dua atau tiga pilihan jawaban. Setelah peneliti memberikan stimulus sebanyak tiga kali, subjek diminta untuk memilih salah satu dari pilihan jawaban tersebut. Apabila subjek mampu menjawab hingga ketepatan 100\%, itu berarti subjek memiliki kemampuan persepsi antara kategori hentian takbersuara dan bersuara. Apabila jawaban benar sebanyak 75\%, itu artinya inkonklusif/ambigu; skor di bawah 50\% menunjukkan bahwa subjek tidak memiliki batas persepsi. Meskipun demikian, teknik yang dipilih oleh peneliti ini sejatinya memiliki unsur keberuntungan. Oleh karenanya, peneliti hanya memakai nilai jawaban yang 100\% benar untuk menentukan apakah seorang subjek memiliki batas persepsi pada bunyi konsonan hentian bersuara dan takbersuara.

Peneliti memberikan dua jenis stimulus kepada subjek, yang satu suku kata (12 stimulus) dan yang dua suku kata (55 stimulus). ${ }^{12}$ Stimulusnya adalah bunyi yang dihasilkan secara alami oleh peneliti. Setiap stimulus dilafalkan tiga

\footnotetext{
${ }^{12}$ Stimulus yang disilabik tidak dipertimbangkan dalam studi ini karena baik subjek dari kelompok kontrol maupun kelompok eksperimen yang mencatatkan hasil 100\%. Kegagalan dari subjek dari kelompok kontrol kemungkinan disebabkan dari faktor bias makna (semantik) yang ditimbulkan dari stimulus. Misalnya, beberapa pasangan stimuli seperti [pipi] yang merupakan leksikon dalam bahasa Indonesia. Selain itu, konsonan di posisi intervokalik juga menyebabkan kesulitan dari aspek saat awal bunyi (voice onset time, VOT) bagi kelompok kontrol. Jadi, meskipun penutur bahasa pertama mendapatkan nilai yang lebih tinggi pada keseluruhan tes, bias yang ditimbulkan oleh faktor makna dan konsonan intervokalik cukup signifikan untuk dikecualikan dalam penelitian ini.
} 
kali dengan jelas di depan subjek. Stimulus pada studi ini bukan dalam bentuk rekaman, dan saat awal bunyi (voice onset time, VOT) tidak dikontrol. Stimuli diberikan dengan urutan acak dan setiap subjek diberitahu demikian. Subjek juga diberitahu bahwa mereka harus menganggap stimulusnya tidak memiliki makna.

Adapun subjek penelitian 8 (delapan) orang subjek orang Taiwan dan 4 (empat) subjek orang Indonesia (kelompok kontrol) direkrut untuk berpartisipasi dalam eksperimen pada bagian persepsi ini. Semua subjek sedang kuliah S1. Semua subjek orang Taiwan berasal dari Taiwan dan yang Indonesia berasal dari beberapa tempat di Indonesia. Setiap subjek mengisi kuesioner tentang latar belakang kebahasaan yang diadopsi dari penelitian Marian, dkk. ${ }^{13}$ Peneliti memperkirakan latar belakang bahasa akan berkontribusi terhadap kemampuan pengenalan bunyi konsonan hentian bersuara bahasa Indonesia. Semua subjek terpapar dua bahasa dari usia dini (early bilinguals). Tujuh subjek orang Taiwan mencantumkan bahasa Mandarin dan bahasa Taiwan sebagai bahasa dominan pertama dan kedua mereka, dan yang satu lagi mencantumkan bahasa Mandarin dan bahasa Hakka masing-masing sebagai bahasa dominan kedua.

Tiga subjek orang Indonesia mencantumkan bahasa Indonesia sebagai bahasa dominan mereka dan satunya lagi mencantumkan bahasa Melayu Bangka dan bahasa Indonesia sebagai bahasa dominan. Dua subjek orang Indonesia mencantumkan bahasa Inggris sebagai bahasa dominan kedua mereka. Salah satu mencantumkan bahasa Jawa sebagai bahasa dominan kedua. Subjek yang mencantumkan bahasa Melayu Bangka dan bahasa Indonesia sebagai bahasa dominan dan mencantumkan bahasa Mandarin sebagai bahasa dominan kedua atau ketiga.

Semua subjek telah terpapar dengan bahasa Inggris di dalam kelas sejak berada di tingkat SD dan semua subjek mencantumkan bahasa Inggris sebagai bahasa dominan ketiga. Enam subjek orang Taiwan mencantumkan bahwa mereka telah memelajari bahasa Indonesia selama 300 jam dalam kelas dan yang

\footnotetext{
${ }^{13}$ Marian, dkk. "The Language Experience and Proficiency Questionnaire (LEAP-Q): Assessing language profiles in bilinguals and multilinguals". Journal of Speech Language and Hearing Research 50(4), hal. 940-967.
} 
Johnny Lee

dua lagi mencantumkan waktu pemelajaran selama 180 jam dalam kelas. Tabel 1 memberikan ringkasan latar belakang kebahasaan dari semua subjek yang berpartisipasi dalam penelitian ini.

Tabel 1. Ringkasan latar belakang kebahasaan subjek

\begin{tabular}{|c|c|c|c|}
\hline Kelompok & Subjek & $\begin{array}{l}\text { Paparan Bahasa Sebelum } \\
\text { Usia Satu Tahun }\end{array}$ & $\begin{array}{c}\text { Bahasa Setelah Usia Satu } \\
\text { Tahun }\end{array}$ \\
\hline kontrol & $\mathrm{Ch}$ & bahasa Indonesia & $\begin{array}{l}\text { bahasa Jawa, bahasa Mandarin, } \\
\text { bahasa Inggris }\end{array}$ \\
\hline kontrol & Mi & bahasa Indonesia & bahasa Inggris, bahasa Mandarin \\
\hline kontrol & Ek & $\begin{array}{l}\text { bahasa Indonesia, bahasa } \\
\text { Hokkien }\end{array}$ & bahasa Inggris, bahasa Mandarin \\
\hline kontrol & $\operatorname{Re}$ & $\begin{array}{l}\text { bahasa Melayu, bahasa, } \\
\text { bahasa Hokkien, bahasa } \\
\text { Indonesian, bahasa Hakka }\end{array}$ & $\begin{array}{l}\text { bahasa Inggris, bahasa Thai, } \\
\text { bahasa Jepang }\end{array}$ \\
\hline eksperimen & $\mathrm{Su}$ & $\begin{array}{l}\text { bahasa Mandarin, bahasa } \\
\text { Taiwan }\end{array}$ & bahasa Inggris, bahasa Indonesia \\
\hline eksperimen & $\mathrm{Pe}$ & $\begin{array}{l}\text { bahasa Mandarin, bahasa } \\
\text { Taiwan }\end{array}$ & bahasa Inggris, bahasa Indonesia \\
\hline eksperimen & $\mathrm{Ja}$ & $\begin{array}{l}\text { bahasa Mandarin, bahasa } \\
\text { Taiwan }\end{array}$ & $\begin{array}{l}\text { bahasa Taiwan, bahasa Inggris, } \\
\text { bahasa Indonesia, bahasa Jepang }\end{array}$ \\
\hline eksperimen & $\mathrm{Ha}$ & $\begin{array}{l}\text { bahasa Mandarin, bahasa } \\
\text { Hakka }\end{array}$ & $\begin{array}{l}\text { bahasa Taiwan, bahasa Inggris, } \\
\text { bahasa Indonesia, bahasa Korea }\end{array}$ \\
\hline eksperimen & Jo & $\begin{array}{l}\text { bahasa Mandarin, bahasa } \\
\text { Taiwan }\end{array}$ & $\begin{array}{l}\text { bahasa Taiwan, bahasa Inggris, } \\
\text { bahasa Indonesia }\end{array}$ \\
\hline eksperimen & $\mathrm{Xi}$ & $\begin{array}{l}\text { bahasa Mandarin, bahasa } \\
\text { Taiwan }\end{array}$ & $\begin{array}{l}\text { bahasa Inggris, bahasa Indonesia, } \\
\text { bahasa Burma }\end{array}$ \\
\hline eksperimen & $\mathrm{Ti}$ & $\begin{array}{l}\text { bahasa Mandarin, bahasa } \\
\text { Taiwan }\end{array}$ & bahasa Inggris, bahasa Indonesia \\
\hline eksperimen & $\mathrm{La}$ & bahasa Mandarin & $\begin{array}{l}\text { bahasa Taiwan, bahasa Inggris, } \\
\text { bahasa Indonesia }\end{array}$ \\
\hline
\end{tabular}

Penelitian ini menggunakan tugas diskriminasi (discrimination task) untuk mengetahui kemampuan persepsi pemelajar Taiwan terhadap bunyi konsonan hentian bersuara; untuk mengetahui apakah pemelajar Taiwan mampu menentukan batas fonem (phonemic boundary) untuk fitur suara konsonan hentian. Studi ini menggunakan tes pelabelan di mana diberikan dua atau tiga pilihan jawaban. Setelah peneliti memberikan stimulus sebanyak tiga kali, subjek diminta untuk memilih salah satu dari pilihan jawaban tersebut. 
Apabila subjek mampu menjawab hingga ketepatan 100\%, itu berarti subjek memiliki kemampuan persepsi antara kategori hentian takbersuara dan bersuara. Apabila jawaban benar sebanyak 75\%, itu artinya inkonklusif/ambigu; skor di bawah 50\% menunjukkan bahwa subjek tidak memiliki batas persepsi. Meskipun demikian, teknik yang dipilih oleh peneliti ini sejatinya memiliki unsur keberuntungan. Oleh karenanya, peneliti hanya memakai nilai jawaban yang $100 \%$ benar untuk menentukan apakah seorang subjek memiliki batas persepsi pada bunyi konsonan hentian bersuara dan takbersuara.

Peneliti memberikan dua jenis stimulus kepada subjek, yang satu suku kata (12 stimulus) dan yang dua suku kata (55 stimulus). ${ }^{14}$ Stimulusnya adalah bunyi yang dihasilkan secara alami oleh peneliti. Setiap stimulus dilafalkan tiga kali dengan jelas di depan subjek. Stimulus pada studi ini bukan dalam bentuk rekaman, dan saat awal bunyi (voice onset time, VOT) tidak dikontrol. Stimuli diberikan dengan urutan acak dan setiap subjek diberitahu demikian. Subjek juga diberitahu bahwa mereka harus menganggap stimulusnya tidak memiliki makna.

\section{Pembahasan}

Hasil 1: Batas persepsi konsonan hentian bilabial bersuara dan takbersuara [b]-[p]. Tabel 2 dan 3 menunjukkan angka ketepatan diskriminasi kategori bunyi bilabial, [b]-[p], untuk skor kelompok dan perorangan.

Tabel 2. Angka ketepatan diskriminasi bunyi [b]-[p] untuk subjek dari kelompok kontrol

\begin{tabular}{lllll}
\hline Kelompok & \multicolumn{4}{l}{ Kelompok Kontrol } \\
\hline Subjek & $\mathrm{Ch}$ & $\mathrm{Mi}$ & $\mathrm{Ek}$ & $\mathrm{Re}$ \\
Persentase jawaban benar & $100.00 \%$ & $100.00 \%$ & $100.00 \%$ & $100.00 \%$ \\
\hline
\end{tabular}

14 Stimulus yang disilabik tidak dipertimbangkan dalam studi ini karena baik subjek dari kelompok kontrol maupun kelompok eksperimen yang mencatatkan hasil 100\%. Kegagalan dari subjek dari kelompok kontrol kemungkinan disebabkan dari factor bias makna (semantik) yang ditimbulkan dari stimulus. Misalnya, beberapa pasangan stimuli seperti [pipi] yang merupakan leksikon dalam bahasa Indonesia. Selain itu, konsonan di posisi intervokalik juga menyebabkan kesulitan dari aspek saat awal bunyi (voice onset time, VOT) bagi kelompok kontrol. Jadi, meskipun penutur bahasa pertama mendapatkan nilai yang lebih tinggi pada keseluruhan tes, bias yang ditimbulkan oleh faktor makna dan konsonan intervokalik cukup signifikan untuk dikecualikan dalam penelitian ini. 
Tabel 3. Angka ketepatan diskriminasi [b]-[p] untuk subjek dari kelompok eksperimen

\begin{tabular}{|c|c|c|c|c|c|c|c|c|}
\hline Kelompok & Kelomp & k Eksper & nen & & & & & \\
\hline Subjek & $\mathrm{Su}$ & $\mathrm{Pe}$ & $\mathrm{Ja}$ & $\mathrm{Ha}$ & Jo & $\mathrm{Xi}$ & $\mathrm{Ti}$ & $\mathrm{La}$ \\
\hline $\begin{array}{l}\text { Persentase } \\
\text { jawaban } \\
\text { benar }\end{array}$ & $75.00 \%$ & $75.00 \%$ & $75.00 \%$ & $25.00 \%$ & $25.00 \%$ & $100.00 \%$ & $100.00 \%$ & $100.00 \%$ \\
\hline
\end{tabular}

Seperti yang terlihat pada dua tabel di atas, subjek dari kelompok kontrol menunjukkan angka sempurna untuk pembedaan dua kategori fonem pada stimulus satu suku kata. Tiga subjek dari kelompok eksperimen menunjukkan angka ketepatan diskriminasi yang sempurna pada stimulus; Tiga subjek yang lain menunjukkan hasil yang ambiqu karena hanya mendapatkan nilai $75 \%$ pada tugas eksperimen; dua subjek dari kelompok eksperimen kesulitan dengan stimulus. Hasil ini menunjukkan bahwa subjek-subjek yang mampu membedakan kontras [b]-[p] mempunyai kemampuan persepsi fitur suara pada konsonan hentian bilabial.

Hasil 2: Batas persepsi konsonan hentian alveolar [d]-[t]. Tabel 4 dan 5 menunjukkan gambaran yang jelas terhadap angka ketepatan diskriminasi kategori bunyi alveolar untuk kelompok dan perorangan.

Tabel 4. Angka ketepatan diskriminasi [d]-[t] untuk subjek dari kelompok kontrol

\begin{tabular}{lllll}
\hline Kelompok & \multicolumn{4}{l}{ Kelompok kontrol } \\
\hline Subjek & $\mathrm{Ch}$ & $\mathrm{Mi}$ & $\mathrm{Ek}$ & $\mathrm{Re}$ \\
Persentase jawaban benar & $100.00 \%$ & $100.00 \%$ & $100.00 \%$ & $100.00 \%$ \\
\hline
\end{tabular}

Tabel 5. Angka ketepatan diskriminasi [d]-[t] untuk subjek dari kelompok eksperimen

\begin{tabular}{lllllllll}
\hline Kelompok & \multicolumn{2}{l}{ Kelompok Eksperimen } & & & & & \\
\hline Subjek & $\mathrm{Su}$ & $\mathrm{Pe}$ & $\mathrm{Ja}$ & $\mathrm{Ha}$ & $\mathrm{Jo}$ & $\mathrm{Xi}$ & $\mathrm{Ti}$ & $\mathrm{La}$ \\
$\begin{array}{l}\text { Persentase } \\
\text { jawaban }\end{array}$ & $50.00 \%$ & $50.00 \%$ & $50.00 \%$ & $25.00 \%$ & $75.00 \%$ & $100.00 \%$ & $100.00 \%$ & $100.00 \%$ \\
benar & & & & & & & & \\
\hline
\end{tabular}

Subjek kelompok kontrol dan tiga subjek yang mampu membedakan [b]-[p] pada kelompok eksperimen menunjukkan angka ketepatan diskriminasi sempurna. Salah satu dari kelompok eksperimen menunjukkan angka ketepatan 
diskriminasi yang ambigu (75\%) dan empat subjek yang lain tidak memiliki batas persepsi $[\mathrm{d}]-[\mathrm{t}]$.

Hasil 3: Batas persepsi konsonan hentian velar [g]-[k]. Tabel 6 dan 7 berikut menunjukkan kemampuan mendiskriminasikan $[\mathrm{g}]-[\mathrm{k}]$.

Tabel 6. Angka ketepatan diskriminasi $[\mathrm{g}]-[\mathrm{k}]$ untuk kelompok kontrol

\begin{tabular}{lllll}
\hline Kelompok & \multicolumn{4}{l}{ Kelompok Kontrol } \\
\hline Subjek & $\mathrm{Ch}$ & $\mathrm{Mi}$ & $\mathrm{Ek}$ & $\mathrm{Re}$ \\
Persentase jawaban benar & $100.00 \%$ & $100.00 \%$ & $100.00 \%$ & $100.00 \%$ \\
\hline
\end{tabular}

Tabel 7. Angka ketepatan diskriminasi $[\mathrm{g}]-[\mathrm{k}]$ untuk kelompok eksperimen

\begin{tabular}{lllllllll}
\hline Group & \multicolumn{2}{l}{ Experimental Group } \\
\hline Subject & $\mathrm{Su}$ & $\mathrm{Pe}$ & $\mathrm{Ja}$ & $\mathrm{Ha}$ & $\mathrm{Jo}$ & $\mathrm{Xi}$ & $\mathrm{Ti}$ & $\mathrm{La}$ \\
$\begin{array}{l}\text { Percentage } \\
\text { correct }\end{array}$ & $50.00 \%$ & $75.00 \%$ & $100.00 \%$ & $00.00 \%$ & $25.00 \%$ & $25.00 \%$ & $75.00 \%$ & $100.00 \%$ \\
\hline
\end{tabular}

Mengenai angka ketepatan diskriminasi bunyi hentian velar bersuara, seluruh subjek kelompok kontrol dan dua subjek eksperimental menghasilkan angka ketepatan 100\%. Sisanya inkonklusif atau tidak bisa dengan tepat membedakan fitur suara pada bunyi hentian velar.

Dari tugas diskriminasi yang diberikan, semua subjek pada kelompok kontrol mencatatkan angka ketepatan sempurna. Namun, hanya ada satu peserta pada kelompok eksperimen. La, yang mampu menjawab dengan ketepatan 100\%. Hal ini menarik karena La adalah salah satu subjek yang tidak mencantumkan bahasa Taiwan, memiliki kontras pada fitur suara, sebagai bahasa yang terpapar kepadanya sewaktu usia anak. Hasil tersebut juga menunjukkan bahwa subjek, pemelajar Taiwan, tidak mampu secara sempurna membedakan fitur suara pada bunyi hentian melalui sumber akustik yang dilafalkan oleh peneliti. Kemampuan subjek dalam berbahasa Taiwan, yang memiliki fonem distingtif pada fitur suara, $[\mathrm{b}]-[\mathrm{p}]$ dan $[\mathrm{g}]-[\mathrm{k}]$, juga tidak secara otomatis menyediakan kemampuan persepsi yang memadai untuk subjek. Selain itu, meskipun subjek telah terlatih untuk melafalkan bunyi hentian bersuara dalam bahasa Inggris dan bahasa Indonesia, sistem fonologi untuk kategori persepsi belum terbentuk baik karena hanya satu dari delapan subjek eksperimen yang mampu dengan sempurna membedakan fitur suara bunyi hentian. 
Ketidakmampuan subjek eksperimen untuk memberikan jawaban yang $100 \%$ tepat dapat dikarenakan beberapa alasan spekulatif, sebagai berikut: pertama, kurangnya paparan terhadap bahasa Taiwan pada usia dini. Jadi, meskipun bahasa Taiwan memiliki kontras pada fitur suara di dua set fonem hentian, mereka belum mampu secara sempurna membedakan bunyi tersebut dan dalam tahapan pemerolehan fitur ini ke dalam sistem kebahasaan seperti hasil kajian Bradlow, dkk.15. Kemungkinan ini dapat diketahui dari jawaban 7 subjek yang menggunakan bahasa Mandarin sebagai bahasa dominan mereka, bukan bahasa Taiwan; kedua, saat awal bunyi (voice onset time, VOT) pada bunyi hentian bersuara bahasa Taiwan dan bahasa Indonesia kemungkinan berbeda dan subjek pemelajar Taiwan tidak bisa membedakannya; ketiga, paparan subjek kepada bahasa Inggris masih belum cukup memadai untuk membentuk kategori baru pada kemampuan persepsi fitur suara meskipun subjek sudah memelajari bahasa Inggris selama 10 tahun; keempat, subjek masih belum mampu membedakan bunyi setiap karakter bahasa Indonesia ataupun subjek tidak sadar menggunakan tata bahasa fonologi bahasa Inggris yang memiliki keharusan aspirasi pada bunyi hentian takbersuara di awal kata sewaktu mengerjakan tes ini; terakhir, ketidaktepatan juga bisa disebabkan oleh kurangnya kontrol peneliti terhadap saat awal bunyi (voice onset time, VOT).

Penelitian ini memiliki kekurangan dalam hal desain penelitian dan jumlah subjek yang kecil. Namun demikian, peneliti berharap tulisan yang didukung dengan beberapa rujukan kepustakaan ini setidaknya bisa menjelaskan fenomena pemelajar Taiwan pada tahapan ini membuat kekeliruan (tertukarnya) produksi tulisan untuk kata yang memiliki huruf b-p, d-t, dan g-k.

\section{Penutup}

Berdasarkan uraian penelitian di atas dapat disimpulkan beberapa hal. Pertama tiga dari delapan subjek pemelajar Taiwan (kelompok eksperimen) atau sekitar 37\% mampu secara sempurna atau $100 \%$ melakukan pembedaan presepsi bunyi [b] dan [p], sisanya tidak secara baik membedakan dua bunyi tersebut. Hasil kedua, tiga dari delapan atau sekitar 37\% pemelajar Taiwan

\footnotetext{
${ }^{15}$ Bradlow, dkk. "Training Japanese listeners to identify English ....
} 
mampu dengan sempurna (100\%) pembedaan presepsi bunyi $[\mathrm{d}] \mathrm{dan}[\mathrm{t}]$. Terakhir, dua pemelajar Taiwan atau sekitar 25\% mampu pembedaan presepsi bunyi $[\mathrm{g}]$ dan $[\mathrm{k}]$. Penelitian lanjutan dapat menggunakan alat spektograf yang lebih terukur untuk membandingkan nilai akustik pada pelafalan bahasa Indonesia dan Mandarin.

\section{Ucapan Terima Kasih}

Peneliti mengucapkan terima kasih kepada semua subjek yang berpartisipasi dalam penelitian ini dan tim redaksi Jurnal Aksis yang sudah berkontribusi dalam penyelesaian serta perbaikan penulisan artikel ini.

\section{Daftar Pustaka}

Bradlow, A. R., Pisoni, D. B., Akahane-Yamada, R., \& Tohkura, Y. (1997). TrainingJapanese listeners to identify English /r/ and /l/: IV. Some effects of perceptual learning on speech production. Journal of the Acoustical Society of America, 101,2299-2310. Diakses dari: https://asa.scitation.org/doi/pdf/10.1121/1.418276

Carroll, David W. Phychology of Language Fifth Edition. Australia: Thomson Wandswort. 2008

Flege, J. "The instrumental study of L2 speech production: Some methodological considerations". Language Learning, 37, 1987. 285296.

Hayward, Katrina. Experimental Phonetics: An Introduction. New York: Routledge. 2014.

Kuhl, Patricia. (2000). A new view of language acquisition. Proceedings of the National Academy of Sciences, 97(22), p. 175-190. Diakses dari: https://www.ncbi.nlm.nih.gov/pmc/articles/PMC34178/pdf/pq011850.pdf

Kuhl, Patricia. (2004). Early language acquisition: cracking the speech code. Nature reviews neuroscience, 5(11), p. 831-843. Diakses dari: https://faculty.washington.edu/losterho/kuhl_nature_neuroscience_revi ews_2004.pdf

Marian, V., Blumenfeld, H. K., \& Kaushanskaya, M. (2007). The Language Experience and Proficiency Questionnaire (LEAP-Q): Assessing language profiles in bilinguals and multilinguals. Journal of Speech 
Language and Hearing Research 50(4):940-67. Diakses dari: https://pubs.asha.org/doi/pdf/10.1044/1092-4388\%282007/067\%29

Reetz dan Jongman. Phonetics: Transcription, Production, Acoustics, and Perception, New York: John Wiley \& Sons, 2011.

Miyawaki, K., Strange, W., Verbrugge, R., Liberman, A. M., Jenkins, J. J., \& Fujimura, O. (1975). An effect of linguistic experience: The discrimination of $[\mathrm{r}]$ and [1] by native speakers of Japanese and English. Perception and Psychophysics, 18.5, 331-340. Diakses dari:https://link.springer.com/content/pdf/10.3758/BF03211209.pdf

Wang, Y., Spence, M., Jongman, A., and Sereno, J. (1999). Training American listeners to perceive Mandarin tones. Journal of the Acoustical Society of America 106, 3649-3659. Diakses dari: https://asa.scitation.org/doi/pdf/10.1121/1.428217 